\title{
DETERMINAÇÃO DAS PROPRIEDADES BIOMECÂNICAS DO LIGAMENTO PATELAR DE CÃES (CANIS FAMILIARIS LINNAEUS, 1758)
}

\section{DETERMINATION OF BIOMECHANICAL PROPERTIES OF PATELLAR LIGAMENT IN DOGS (CANIS FAMILIARIS LINNAEUS, 1758)}

\author{
Aline da Costa Constantino ${ }^{1 *}$ \\ Marcelo Domingues de Faria ${ }^{1}$ \\ Nelson Cárdenas Olivier ${ }^{1}$ \\ Joaquim Pereira Neto ${ }^{2}$ \\ Ítalo Barbosa Lemos Lopes ${ }^{1}$ \\ Nayara Reis Cordeiro de Lira ${ }^{1}$
}

${ }^{1}$ Universidade Federal do Vale do São Francisco, Petrolina, PE, Brasil

2Universidade do Estado da Bahia, Juazeiro, BA, Brasil

*Autora para correspondência - line.constantino@hotmail.com

\begin{abstract}
Resumo
$\mathrm{O}$ estudo biomecânico de ligamentos articulares geram subsídios às pesquisas de biomateriais ou técnicas de tratamento para substituição ou reparação destas estruturas por ocasião de ruptura ou degeneração. Diante disto, realizaram-se ensaios biomecânicos de tração do ligamento patelar em 53 cães, totalizando 106 ligamentos patelares testados. Foram determinadas a capacidade máxima de resistência em Newtons $(\mathrm{N})$ e a deformação expressa em milímetros $(\mathrm{mm})$, sendo estes dados correlacionados à biometria corporal dos cadáveres dos cães utilizados. A resistência do ligamento patelar direito e esquerdo no grupo das fêmeas foi de $642,6 \mathrm{~N} \pm 297,2 \mathrm{~N}$ e $627,0 \mathrm{~N} \pm 300,6 \mathrm{~N}(\mathrm{p}=0,028)$, respectivamente. Nos machos, verificaram-se valores superiores $(\mathrm{p}=0,035)$. O ligamento patelar direito teve capacidade máxima de resistência de $850,8 \mathrm{~N} \pm 299,9 \mathrm{~N}$ e o esquerdo $729,3 \mathrm{~N} \pm 283,5 \mathrm{~N}$. Estatisticamente, foi evidenciado que não há correlação significativa $(r>0,7)$ entre os parâmetros biométricos corporais aferidos e a resistência ou deformação do ligamento patelar. Mesmo não havendo correlação estatística significativa, os dados de resistência e deformação do ligamento patelar canino podem gerar embasamento para outras pesquisas, que visam corrigir rupturas de ligamentos articulares.
\end{abstract}

Palavras-chave: joelho; ligamento patelar; resistência.

\begin{abstract}
The biomechanical study of articular ligaments generate subsidies for research of biomaterials or treatment techniques for replacement or repair of these structures on the occasion of rupture or degeneration. Therefore, We carried out a biomechanical traction assay of the patellar ligament in 53 dogs, totaling 106 patellar ligaments, determining maximum resistance in Newtons $(\mathrm{N})$ and deformation in millimeters $(\mathrm{mm})$. These data were correlated to body biometrics of the dogs used. The strength of the left and right patellar ligaments in the female group were $642.6 \mathrm{~N} \pm 297.2 \mathrm{~N}$ and $627.0 \mathrm{~N} \pm 300.6 \mathrm{~N}(\mathrm{p}=0.028)$, respectively. Males presented higher values $(\mathrm{p}=0.035)$. The right patellar ligament had a maximum capacity of resistance of $850.8 \mathrm{~N} \pm 299.9 \mathrm{~N}$, and the left one of $729.3 \mathrm{~N}$ $\pm 283.5 \mathrm{~N}$. Statistically, there is no significant correlation ( $r>0.7)$ between the biometric parameters measured and the bodily strength or deformation of the patellar ligament. Despite no statistical significant correlation, data from the strength and deformation of the canine patellar ligament can support further research aimed at correcting ruptures of joint ligaments.
\end{abstract}


Keywords: knee; patellar ligament; resistance.

Enviado em: 01 setembro 2013

Aceito em: 18 janeiro 2016

\section{Introdução}

O ligamento patelar, como parte distal do mecanismo extensor do joelho, tem como função transmitir toda a força de tração do quadríceps, recebida pela patela, para a tuberosidade anterior da tíbia ${ }^{(1)}$. Os ligamentos são constituídos predominantemente por colágeno, estrutura em forma de tripla hélice com capacidade variável de reter líquidos em função da solicitação mecânica. A deformação de um tecido puramente elástico é diretamente proporcional à força aplicada, enquanto que as propriedades de um tecido viscoso são dependentes do tempo e da velocidade de aplicação da força. Tecidos biológicos apresentam propriedades elásticas e viscosas, o que lhes confere um comportamento viscoelástico ${ }^{(2)}$. Esse comportamento determina que as estruturas do aparelho locomotor sejam mais adaptadas às solicitações mecânicas em alta velocidade ou aos impactos que ocorram constantemente ao longo da $\operatorname{vida}^{(3)}$.

O terço central do ligamento patelar é o enxerto mais frequentemente utilizado na reconstrução dos ligamentos cruzados anterior e posterior ${ }^{(1,4)}$. Diante desta condição, é possível constatar que os principais estudos biomecânicos realizados até agora buscam avaliar a eficácia de técnicas cirúrgicas e tratamentos ${ }^{(3,5)}$. Todavia, para avaliar a eficácia de tais procedimentos, é importante conhecer os aspectos biomecânicos das estruturas anatômicas íntegras para, então, tornar os resultados obtidos valores considerados fisiologicamente normais.

Analisando a literatura em biomecânica a respeito do ligamento patelar, é possível verificar que as características mecânicas deste ligamento têm sido mais estudadas em cadáveres humanos ou outros modelos experimentais, como a ovelha. Além disto, estas pesquisas nem sempre utilizam ligamentos íntegros, mas têm o intuito de avaliar alguma intervenção sobre os mesmos ${ }^{(5,6,7)}$. Desta forma, o presente estudo teve como objetivos determinar a capacidade máxima de resistência e deformação do ligamento patelar de cães, estabelecendo possíveis correlações com os parâmetros biométricos corporais e as dimensões do mesmo ligamento.

\section{Material e métodos}

Mediante aprovação do Comitê de Ética da Universidade Federal do Vale do São Francisco (Univasf), sob protocolo $n^{\circ} 27051115$, foram coletados 53 cadáveres de cães, com no máximo três horas postmortem, sendo 24 machos e 29 fêmeas, de raça cruzada, adultos, porte médio, oriundos do Centro de Controle de Zoonoses do Município de Petrolina, Pernambuco, Brasil.

Inicialmente, foi aferida a biometria corporal dos cães. Em balança analítica digital (Techline ${ }^{\circledR}$, São Paulo - SP, Brasil) foi aferida a massa corporal dos animais utilizados na amostra, expressa em quilogramas. Com fita métrica e paquímetro, determinaram-se os seguintes parâmetros, expressos em centímetros:

- comprimento corporal: espaço entre a crista nucal e a inserção da cauda;

- altura corporal: compreendida da extremidade distal do membro torácico à região do ombro, situada entre as escápulas;

- cintura escapular: medida entre as espinhas escapulares contra-laterais;

- cintura pélvica: medida entre as tuberosidades coxais das asas ilíacas;

- altura do tórax: medida entre a base do esterno e os processos espinhosos da sétima ou oitava vértebras torácicas;

- altura do abdome: aferição entre a cicatriz umbilical e os processos espinhosos da terceira ou quarta vértebras lombares;

- comprimento da caixa craniana: intervalo entre a sutura fronto-nasal e a crista nucal; 
- comprimento nasal: intervalo entre o ápice do nariz e a sutura fronto-nasal;

- largura da cabeça: espaço entre as faces laterais dos arcos zigomáticos contra-laterais;

- altura da cabeça: intervalo compreendido entre a crista nucal e o ângulo da mandíbula.

Em sequência, procedeu-se à desarticulação dos membros pélvicos, na altura da articulação coxofemoral. A articulação femoro-tíbio-patelar foi acessada após rebatimento da pele, músculos, tecido adiposo e conjuntivo adjcentes, permitindo a inspeção prévia. Em caso de alterações patológicas, as mesmas eram descartadas.

O ligamento patelar íntegro e em toda sua extensão, desde a patela até sua inserção na crista tibial, foi alcançado após retirados a cápsula articular, os meniscos, os ligamentos colaterais lateral e medial, menisco-femoral, tibiais craniais e caudais dos meniscos e os ligamentos cruzados cranial e caudal. Finalizada a dissecação, promoveu-se a osteotomia da tíbia em seu terço médio, com auxílio de serrafita, a fim de permitir a fixação das peças ósseas às garras superior e inferior da Máquina Universal de Ensaios Eletromecânicos e Microprocessados Digital Line (EMIC® - DL10000, São José dos Pinhais - PR, Brasil) (FIgura 1). Imediatamente após a dissecação e a osteotomia, foram aferidas as espessuras crânio-caudal e médio-lateral do ligamento patelar de cada cadáver animal, em ambos os antímeros, expressas em milímetros $(\mathrm{mm})$.

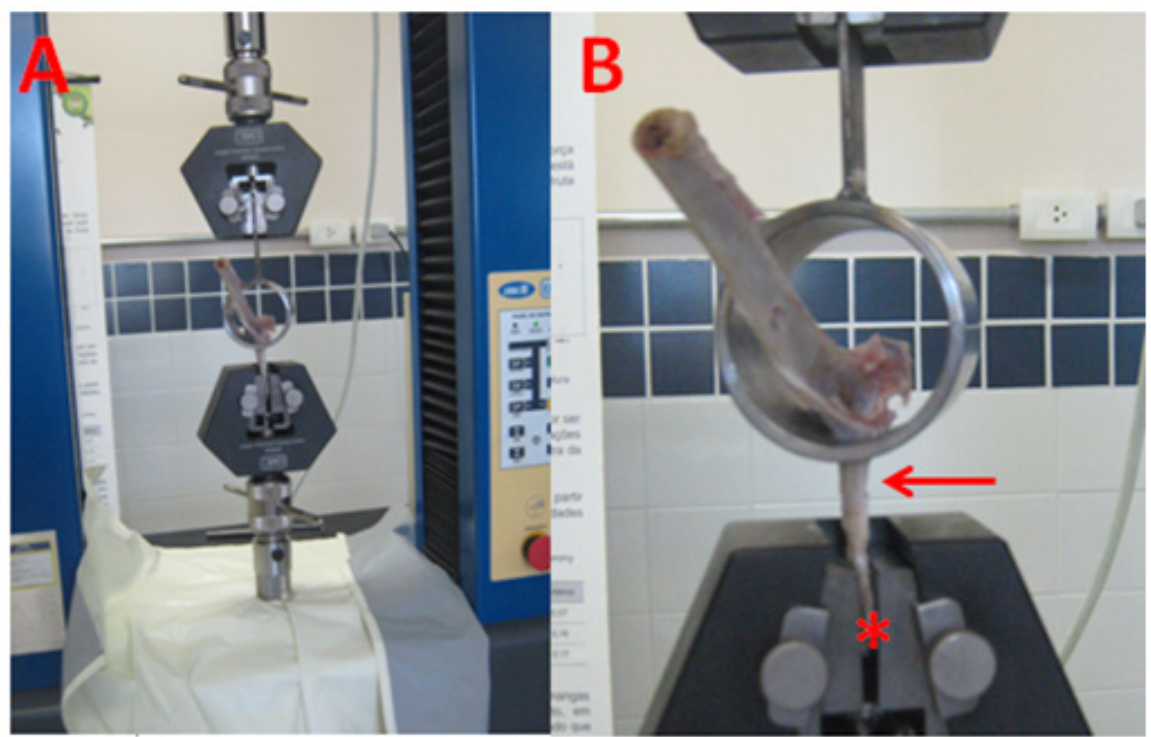

Figura 1: (A) Método de fixação da patela e tíbia à Máquina Universal de Ensaios Eletromecânicos e Microprocessados Digital Line $\left(\mathrm{EMIC}^{\mathrm{2}}\right)$. (B) detalhe evidenciando a fixação da patela (*) na garra inferior e o ligamento patelar (seta).

As articulações foram acondicionadas em sacos plásticos devidamente identificados e armazenadas em freezer a uma temperatura de $-10{ }^{\circ} \mathrm{C}$, por tempo não superior a dois meses. $\mathrm{Na}$ data de realização dos ensaios uniaxiais de tração, as peças anatômicas foram retiradas do freezer e descongeladas por imersão em solução fisiológica, em temperatura ambiente, por, aproximadamente, quatro horas.

A fixação dos corpos de prova às garras da Máquina Universal de Ensaios Eletromecânicos e Microprocessados consistiu na ancoração da tíbia na garra superior, a qual tinha um orifício que permitia a passagem da patela, que foi fixada à garra inferior. Em microcomputador foi realizado o acionamento da máquina, que promoveu a tração da articulação a uma velocidade de $25 \mathrm{~mm} / \mathrm{minuto}$, até que o corpo de prova não oferecesse mais resistência à força aplicada, obtendo-se, desta forma, a capacidade máxima de resistência, expressa em Newtons $(\mathrm{N})$ e a deformação, em milímetros (mm). Os dados biomecânicos das articulações testadas e os parâmetros biométricos corporais foram tabulados, divididos em dois grupos (machos e fêmeas) e submetidos à análise estatística. Todas as variáveis passaram por uma análise preliminar utilizando-se o programa $\mathrm{R}$, no qual foram gerados gráficos Box plot $^{(8)}$, para se detectar possíveis valores discrepantes que pudessem distorcer demasiadamente as médias. O teste "T" de Student, realizado por meio do programa Statistical Analysis System-SAS ${ }^{(9)}$, 
foi empregado na comparação das medias, adotando-se nível de significância menor que $5 \%(\mathrm{p}<0,05)$ e coeficiente de correlação de Pearson maior que $70 \%$ (r>0,7).

\section{Resultados e discussão}

Em relação à biometria corporal, foi possível constatar que todos os parâmetros biométricos corporais nas fêmeas foram inferiores aos obtidos no grupo dos machos, porém, não houve diferença estatística significativa (Tabela 1).

Tabela 1: Dados biométricos corporais dos cães utilizados na amostra da pesquisa - massa corporal expressa em quilogramas e demais mensurações em centímetros - Petrolina, 2012

\begin{tabular}{lcc}
\hline \multicolumn{1}{c}{ Parâmetros } & $\begin{array}{c}\text { Média/Desvio padrão } \\
\text { fềmeas }\end{array}$ & $\begin{array}{c}\text { Média/Desvio padrão } \\
\text { machos }\end{array}$ \\
\hline \hline Massa corporal & $11,31 \pm 3,61$ & $13,59 \pm 4,82$ \\
Altura corporal & $54,08 \pm 6,72$ & $55,12 \pm 7,47$ \\
Comprimento corporal & $65,59 \pm 9,20$ & $69,27 \pm 8,02$ \\
Cintura escapular & $49,10 \pm 5,95$ & $52,59 \pm 7,52$ \\
Cintura pélvica & $40,89 \pm 7,95$ & $42,20 \pm 10,06$ \\
Altura do tórax & $27,23 \pm 3,89$ & $28,68 \pm 3,81$ \\
Altura do abdome & $23,44 \pm 4,39$ & $25,15 \pm 4,22$ \\
Comprimento nasal & $8,07 \pm 1,78$ & $8,70 \pm 1,01$ \\
Comprimento da cabeça & $12,13 \pm 1,63$ & $12,98 \pm 1,53$ \\
Largura da cabeça & $15,36 \pm 1,88$ & $16,98 \pm 1,73$ \\
Altura da cabeça & $12,15 \pm 1,77$ & $13,49 \pm 2,02$ \\
\hline
\end{tabular}

$\mathrm{Na}$ determinação da biometria do ligamento patelar, observou-se que as dimensões do ligamento patelar entre machos e fêmeas são muito semelhantes, sem diferença estatisticamente significativa (Tabela 2).

Tabela 2: Biometria $(\mathrm{mm})$, resistência $(\mathrm{N})$ e deformação $(\mathrm{mm})$ dos ligamentos patelares utilizados no experimento - Petrolina, 2012

\begin{tabular}{lcccc}
\hline \multirow{2}{*}{ Parâmetros } & \multicolumn{2}{c}{ Ligamento patelar direito } & \multicolumn{2}{c}{ Ligamento patelar esquerdo } \\
\cline { 2 - 5 } & Fêmeas & Machos & Fêmeas & Machos \\
\hline \hline & & Biometria \\
Espessura crânio-caudal & $1,37 \pm 0,49$ & $1,33 \pm 0,56$ & $1,31 \pm 0,47$ & $1,37 \pm 0,49$ \\
Espessura médio-lateral & $8,17 \pm 1,00$ & $8,29 \pm 1,26$ & $8,17 \pm 1,03$ & $8,00 \pm 1,35$ \\
& \multirow{4}{c}{ Biomecânica } \\
Resistência & $* 642,6 \pm 297,2$ & $* 850,8 \pm 299,9$ & $* 627,0 \pm 300,6$ & $* 729,3 \pm 283,5$ \\
Deformação & $12,64 \pm 4,40$ & $13,66 \pm 4,88$ & $11,75 \pm 4,44$ & $12.29 \pm 4,98$ \\
\hline Val
\end{tabular}

Valores sobrescritos com asterisco $\left({ }^{*}\right)$ indicam nivel de significância menor que $5 \%(\mathrm{p}<0,05)$ entre fêmeas e machos.

Após dissecação e aferição da biometria corporal e ligamentar, as peças articulares foram congeladas, tendo em vista que não era possível realizar os ensaios mecânicos imediatamente. Segundo Wilchez ${ }^{(10)}$, na pesquisa biomecânica com ligamentos ou tendões, é preciso considerar a forma de conservação. Sendo assim, as amostras foram preservadas sob congelamento a $-10{ }^{\circ} \mathrm{C}$ por, no máximo, 60 dias, conforme indicado por Woo et al. ${ }^{(11)}$, pois neste intervalo de tempo não há interferência sobre as propriedades mecânicas dos ligamentos. Em estudos mais recentes a temperatura de armazenagem foi 
de $-20{ }^{\circ} \mathrm{C}^{(3,12)}$. Já Resende et al. ${ }^{(13)}$ conservaram amostras do ligamento cruzado a $-15{ }^{\circ} \mathrm{C}$.

Conforme proposto por Piedade et al. ${ }^{(12)}$, o descongelamento das articulações foi por imersão em solução fisiológica, sob temperatura de aproximadamente $27^{\circ} \mathrm{C}$. Enquanto Resende et al. ${ }^{(13)}$ não utilizaram solução fisiológica no descongelamento, mas umedeceram o ligamento com esta solução durante os testes mecânicos para evitar a desidratação do tecido.

Durante os ensaios uniaxiais de tração, nenhum corpo de prova sofreu fratura óssea prévia à ruptura do ligamento, que é um fenômeno muito comum em testes biomecânicos de ligamentos. Rodrigues et al. ${ }^{(14)}$ observaram fratura óssea prévia à ruptura do ligamento da cabeça do osso femoral durante sua tração. Resende et al. ${ }^{(13)}$ relataram, em estudo sobre as propriedades mecânicas dos ligamentos cruzados, que nas primeiras tentativas estava ocorrendo ruptura da epífise femoral. Já Brendolan et al. ${ }^{(15)}$ relataram que houve avulsão do côndilo lateral do fêmur antes da ruptura do ligamento cruzado cranial durante ensaio mecânico de tração a uma velocidade de $8 \mathrm{~mm} / \mathrm{min}$.

Partindo do princípio que o ligamento patelar possui comportamento viscoelástico, sendo mais adaptado às solicitações mecânicas em alta velocidade, foi escolhida velocidade de tração de $25 \mathrm{~mm} /$ min. Müller et al. ${ }^{(6)}$, em estudo das propriedades mecânicas do ligamento patelar de cadáveres humanos, adotaram velocidade semelhante, $30 \mathrm{~mm} / \mathrm{min}$. Já Dota et al. ${ }^{(3)}$, em ensaio de tração do ligamento patelar de humanos, optaram por velocidade de $20 \mathrm{~mm} / \mathrm{min}$.

A alta velocidade adotada neste experimento pode ter sido determinante para que não ocorresse fratura óssea prévia, haja vista que, em testes mecânicos, os ligamentos submetidos a ensaios de tração a uma alta velocidade tendem a absorver mais energia e rompem na porção ligamentar, ao passo que em testes a baixas velocidades há tendência em ocorrer avulsão óssea prévia ${ }^{(16)}$. Wang et al. ${ }^{(17)}$ afirmaram que altas velocidades de deformações culminam em maior rigidez, limite de resistência superior, menor deformação e maior densidade de energia para ruptura. Entretanto, para tecidos moles, como o ligamento cruzado anterior, artérias e veias, a taxa de deformação parece exibir efeitos menos significativos nas propriedades mecânicas.

A ruptura de todos os ligamentos patelares testados ocorreu próximo a sua inserção na crista tibial. Haut et al. ${ }^{(4)}$, em estudo sobre as propriedades biomecânicas do ligamento patelar em cães em função da idade, afirmaram que $59 \%$ das preparações falharam por avulsão na patela. Müller et al. ${ }^{(6)}$, por outro lado, relataram que, dos 50 ligamentos patelares humanos testados, 94\% apresentaram ruptura na inserção patelar, $2 \%$ na porção média do ligamento e $4 \%$ em local indeterminado. Lazari e Paccola(7), em seu estudo sobre a resistência do ligamento patelar em ovelhas, observaram que as rupturas nos testes aconteceram no terço proximal na maioria dos casos e junto à patela.

Resende et al. ${ }^{(13)}$ salientaram que muitos fatores são capazes de alterar os resultados dos testes uniaxiais, pois a metodologia encontrada na literatura é variada em muitos aspectos e têm grande influência na caracterização biomecânica de ligamentos. Além das diferenças metodológicas, somase a variação inerente aos tecidos biológicos, cujas propriedades podem variar de indivíduo para indivíduo. Isto reflete em expressiva contradição entre os resultados, o que dificulta a comparação.

Em relação à capacidade máxima de resistência e deformação do ligamento patelar (Tabela 2), notouse que em ambos os antímeros foram obtidos valores inferiores nas fêmeas, comparado ao grupo dos machos, havendo diferença significativa $(\mathrm{p}<0,05)$ entre os sexos. Müller et al. ${ }^{(6)}$ relataram que a resistência do ligamento patelar foi de $1461 \mathrm{~N} \pm 448 \mathrm{~N}$, valor muito superior ao encontrado nesta pesquisa. A discrepância entre estes resultados pode ser atribuída ao fator espécie, visto que o trabalho supramencionado foi realizado em cadáveres humanos.

Pecora et al. ${ }^{(1)}$ ressaltaram que a resistência total e a elasticidade de um ligamento não dependem somente da composição de elementos fibrosos elásticos em relação a fibras colágenas, mas também do arranjo espacial destas fibras e do tamanho e espessura do ligamento como um todo. Portanto, é sabido que as dimensões e consequentemente o arranjo espacial das fibras são diferentes entre humanos e cães e estas influenciam nas propriedades mecânicas dos ligamentos.

Constatou-se que não há correlações significativas $(\mathrm{r}>0,7)$ entre os parâmetros biométricos corporais dos cães e a capacidade máxima de resistência $(p=0,029)$ e deformação $(p=0,024)$ do ligamento patelar. Também não foi detectada correlação significativa entre as dimensões do ligamento patelar e a resistência e deformação do mesmo $(\mathrm{p}=0,037)$. A única correlação significante obtida foi entre a resistência do ligamento patelar direito e esquerdo $(\mathrm{r}=0,81)$. Na literatura, os trabalhos que estabelecem correlações entre características biomecânicas e biometria são escassos ${ }^{(14)}$. Haut et al. ${ }^{(4)}$ estudaram 
possíveis correlações, utilizando como parâmetro as características biomecânicas dos ligamentos patelares e a idade, em cães de 6 meses a 15 anos. Eles concluíram que a carga de ruptura desta estrutura não varia em função da idade, não havendo correlação significativa.

\section{Conclusões}

Os parâmetros biométricos corporais dos cães e as dimensões do ligamento patelar não se correlacionam com a resistência e deformação do mesmo. Os dados biomecânicos do ligamento patelar canino íntegro poderão gerar subsídios à pesquisa de tratamentos que corrijam as rupturas desta estrutura. Por se tratar de um tecido viscoelástico, que muda seu comportamento mecânico diante de fatores como velocidade de tração, forma de fixação, proporção de colágeno/elastina, dentre outros, são necessárias análises biomecânicas mais detalhadas, confrontando outras metodologias com o intuito de padronizar os ensaios mecânicos com ligamentos articulares.

\section{Agradecimentos}

Os pesquisadores agradecem ao Conselho Nacional de Desenvolvimento Científico e Tecnológico (CNPq) pelo apoio e ao Centro de Controle de Zoonoses do Município de Petrolina (PE) pela doação dos cadáveres utilizados na pesquisa.

\section{Referências}

1. Pecora JR, Rodrigues CJ, Rodrigues Junior AJ, Salomão O. Densidade linear do sistema de fibras elásticas dos ligamentos patelar, cruzado anterior e cruzado posterior. Acta Ortop. Bras. 2001;9(1):55-62. Disponível em: http://dx.doi.org/10.1590/S1413-78522001000100007.

2. Taylor DC, Dalton JD, Seaber AV, Garrett WE. Viscoelastic properties of muscle-tendon units. Am. J. Sports Med. 1990;18(3):300-309. Disponível em: http://dx.doi.org/10.1177/036354659001800314.

3. Dota AF, Zenaide MR, Demange MK, Camanho GL, Hernandez AJ. Study of the mechanical properties of the posterior cruciate ligament and patellar tendon on fresh human cadavers after radiofrequency shrinkage. Acta. Ortop. Bras. 2007;15(3):138-142. Disponível em: http://dx.doi.org/10.1590/S1413-78522007000300003.

4. Haut RC, Lancaster RL, Decamp CE. Mechanical properties of the canine patellar tendon: Some correlations with age and the content of collagen. J. Biomech. 1992;25(2):163-173. Disponível em: http://dx.doi. org/10.1016/0021-9290(92)90273-4.

5. Górios C, Hernandez AJ, Amatuzzi MM, Leivas TP, Pereira CAM, Neto RB, Pereira ES. Estudo da rigidez do ligamento cruzado anterior do joelho e dos enxertos para sua reconstrução com o ligamento patelar e com os tendões dos músculos semitendíneo e grácil. Acta. Ortop. Bras. 2001;9(2):26-40. Disponível em: http://dx.doi. org/10.1590/S1413-78522001000200004.

6. Müller SS, Silvares PRA, Pereira HR, Silva MAM, Sardenberg T, Leivas TP. Análise comparativa das propriedades mecânicas do ligamento da patela e do tendão calcâneo. Acta. Ortop. Bras. 2004;12(3):134-140. Disponível em: http://dx.doi.org/10.1590/S1413-78522004000300001.

7. Lazari LC, Paccola CAJ. Resistência mecânica do ligamento patelar após retirada do terço médio com incisão longitudinal ou duas mini-incisões transversas. Rev. Bras. Ortop. 2010;45(2):186-190. Disponível em: http://dx.doi.org/10.1590/S0102-36162010000200014.

8. Tukey JW. Exloratory data analysis. 1 ed Boston: Adison-Wesley; 1977. 688p.

9. SAS Institute. Statical Analysis System: user guide [CD-ROM]. Version 9. Cary (NY): SAS Institute Inc., 2003. 
10. Wilchez, DFT. Estudo do comportamento mecânico de ligamentos e tendões utilizando medição ótica. 108 f. Dissertação (Mestrado em Engenharia Mecânica) - Universidade Federal de Santa Catarina, Florianopólis, 2012. Disponível em: https://repositorio.ufsc.br/handle/123456789/99305.

11. Woo S, Orlando C, Camp JF, Akeson WH. Effects of posmortem storage by freezing on ligament tensile behavior. J. Biomech. 1986;19(5):399-404. Disponível em: http://dx.doi.org/10.1016/0021-9290(86)90016-3.

12. Piedade SR, Fabbro IM, Vidal BC, Gamba R. Ensaio uniaxial de tração dos tendões dos músculos grácil e semitendinoso humanos. Acta Ortop. Bras. 2001;9(1):5-11. Disponível em: http://dx.doi.org/10.1590/S141378522001000100001.

13. Resende JL, Faria MTF, Casas EB, Saffar JME, Oliveira EA. Determinação das propriedades mecânicas dos ligamentos cruzados via ensaios uniaxiais de tração. Braz. J. Biomec. 2008;9(17):73-80. Disponível em: http://citrus.uspnet.usp.br/biomecan/ojs/index.php/rbb/article/view/28/79.

14. Rodrigues ECC, Faria MD, Olivier NC, Neto JP. Resistência do ligamento da cabeça do osso femoral em cães. Cienc. Anim. Bras. 2012;13(4):525-533. Disponível em: http://dx.doi.org/10.5216/cab.v13i4.17173.

15. Brendolan AP, Rezende CMF, Pereira MM. Propriedades biomecânicas da fáscia lata e do ligamento cruzado cranial de cães. Arq. Bras. Med. Vet. Zootec. 2001;53(1):27-36. Disponível em: http://dx.doi.org/10.1590/ $\underline{\text { S0102-09352001000100005. }}$.

16. Noyes FR, Delucas JL, Torvik PJ. Biomechanics of anterior cruciate ligament failure: an analysis of strainrate sensitivity and mechanisms of failure in primates. J. Bone Joint Surg. 1974;56(2):236-253. Disponível em: http://jbjs.org/content/56/2/236.

17. Wang JL, Parnianpour M, Shirazi-Adl A, Engin AE. Failure criterion of collagen fiber: viscoelastic behavior simulated by using load control data. Theor. Appl. Fract. Mech. 1997;27(1):1-12. Disponível em: http://dx.doi. org/10.1016/S0167-8442(97)00002-5. 